\title{
Acupuncture May Stimulate Anticancer Immunity via Activation of Natural Killer Cells
}

\author{
Michael Francis Johnston, ${ }^{1}$ Elizabeth Ortiz Sánchez, ${ }^{2}$ Nikola L. Vujanovic, ${ }^{3}$ and Wenhui Li ${ }^{4}$ \\ ${ }^{1}$ Department of Medicine, University of California, USA \\ ${ }^{2}$ Division of Surgical Oncology, Department of Surgery, University of California, Los Angeles, CA, USA \\ ${ }^{3}$ University of Pittsburgh Cancer Institute, Departments of Pathology and Immunology, University of Pittsburgh, Pittsburgh, PA, USA \\ ${ }^{4}$ Department of Chemistry, University of California, Los Angeles, CA, USA
}

Correspondence should be addressed to Michael Francis Johnston, johnston@ucla.edu

Received 3 February 2009; Accepted 19 December 2009

Copyright (c) 2011 Michael Francis Johnston et al. This is an open access article distributed under the Creative Commons Attribution License, which permits unrestricted use, distribution, and reproduction in any medium, provided the original work is properly cited.

\begin{abstract}
This article presents the hypothesis that acupuncture enhances anticancer immune functions by stimulating natural killer (NK) cells. It provides background information on acupuncture, summarizes the current scientific understanding of the mechanisms through which NK cells act to eliminate cancer cells, and reviews evidence that acupuncture is associated with increases in NK cell quantity and function in both animals and humans. The key contribution of this article involves the use of cellular immunology and molecular biological theory to interpret and synthesize evidence from disparate animal and human studies in formulating the 'acupuncture immuno-enhancement hypothesis': clinicians may use acupuncture to promote the induction and secretion of NK-cell activating cytokines that engage specific NK cell receptors that endogenously enhance anticancer immune function.
\end{abstract}

\section{Introduction}

Compelling research findings demonstrate that acupuncture reduces the incidence of chemotherapy-induced acute vomiting [1]. Suggestive findings show that clinicians could use acupuncture to potentially manage cancer-related pain of articular and soft tissue origin [2-7]. Promising evidence suggests that acupuncture relieves fatigue in cancer patients and survivors $[5,6,8,9]$. Preliminary results are accumulating that acupuncture alleviates cancer-related neurological issues, breathlessness, hot flashes and xerostomia [5-7]. In sum, there are substantial empirical grounds to assume that clinicians could use acupuncture to help patients better tolerate conventional cancer therapies by reducing associated side-effects [1-8]. Further, the evidence is very strong that acupuncture is an extremely safe therapy [10]. In short, the research implies that acupuncture is a helpful, versatile and safe treatment modality for patients with cancer.

Despite potential benefits, however, the conventional oncology community has shown itself reluctant to integrate acupuncture and other complementary and alternative medicine (CAM) modalities into their treatment plans for patients with cancer [11]. One concern is that symptoms treated with CAM modalities are often transitory, which opens the possibility that symptomatic relief may be due to spontaneous remission rather than resulting from a CAM intervention [12-14]. A second concern is that the current procedures of disclosure may undermine informed consent and thereby compromise patient autonomy in such a way that produces negative consequences for conventional therapeutic procedures [15]. A third and related concern is that the scientific community lacks both the scientific evidence and biomedical understanding to reasonably suppose that CAM procedures may increase either survival or disease-free survival of patients with cancer [12-14].

We address these concerns by harnessing theory from cellular immunology and molecular biology to interpretive and synthesize disparate empirical studies into a hypothesis about specific mechanisms through which acupuncture enhances anticancer immune function with implications for prevention and management of the cancer. Specifically, we hypothesize that clinicians may use acupuncture to increase the cytotoxic activity of natural killer (NK) cells by promoting cross-talk between the neurotransmitter network and immune system that is [1] orchestrated by nitric oxide, $\beta$-endorphins and cytokines and [2] anchored by opioid 
and NK cell receptors. We refer to this as the "acupuncture immuno-enhancement hypothesis". For reasons we describe below, we think that one acupuncture point is pivotal although we also expect that treatment protocols involving synergistic points will produce better results. But this detail should not distract the reader from our overall theme: acupuncture can be employed to improve the function and level of NK cells. Our main theme is of great importance to patients with cancer (and the conventional providers who treat them) because NK cells are immune cells known to play a key role in directly killing cancer cells and regulating anticancer immune functions [16-18].

To develop the hypothesis that acupuncture enhances endogenous anticancer immune functions with implications for molecular-level carcinogenic control, we begin with a primer on acupuncture and a review of studies that have investigated the impact of acupuncture stimulation on NK cell function in animals and humans. We then provide an overview of the advancing molecular biological understanding of NK cells. Our key contribution follows in the subsequent section, where we harness cellular immunology and molecular biological theories to interpret and integrate disparate research findings in formulating a hypothesis. Specifically, we hypothesize that acupuncture stimulation enhances NK cell stimulating cytokines and NK cell anticancer cytotoxic activity and proliferation through specific cellular and molecular mechanisms, thus enhancing host resistance to cancer in both rodents and humans. As a finale, we assess the evidential basis of our hypothesis and point to fresh research frontiers.

\section{Acupuncture: Three Clinically Important Acupoints}

Acupuncture encompasses a heterogeneous set of needling methods by which practitioners induce biologic responses that activate pathways in the peripheral and central nervous systems [19]. Conventionally, acupuncture involves insertion of a very thin needle into acupoints and is sometimes accompanied by thrusting and/or twirling. One specific type of acupuncture involves transmitting weak pulses of electrical current through acupuncture needles inserted into acupuncture points. In some instances, the distinction is clinically relevant. For example in the case of chemotherapyinduced acute vomiting [1], the evidence indicates that acupuncture administered with electricity (electroacupuncture) is effective although acupuncture without electricity (manual acupuncture) is not. Acupoints are in the vicinity of peripheral nerves and their bifurcations, neuromuscular attachments, blood vessels and ligaments [20]. The World Health Organization identifies 361 precisely-specified anatomically distinct sites known as acupoints [21].

Three of the most commonly used acupoints are Stomach 36 (ST36, in Chinese Zusanli), Pericardium 6 (PC6, in Chinese Neiguan) and Large Intestine 4 (LI4, in Chinese $\mathrm{Hegu}$ ). PC6, known as the "antinausea acupoint", is located between the tendons of palmaris longus and flexor carpii radialis at 2 body-inches (a body-inch or a cun is the greatest width of a patient's thumb at the distal phalanx) above the wrist crease [22]. Stimulation of PC6 is found to be beneficially associated with the prevention and relief of nausea and/or vomiting in three separate reviews published by the Cochrane collaboration, a highly prestigious international initiative that involves the application of a rigorous process to systematically review the effects of biomedical interventions in randomized controlled trials across all areas of health care $[23,24]$. The reviews are based on evidence from clinical trials, many of which are focused specifically on PC6, that involve thousands of patients who experienced relief of nausea and/or vomiting associated with surgery [25], chemotherapy [1] or pregnancy [26]. Furthermore, a recently published randomized controlled trial found acupuncture as effective as commonly used antiemetic drugs in relieving nausea [27].

LI4 is the most commonly used analgesic acupoint, especially for neck and head pain; it is known as the "antipain acupoint" [28]. LI4 is located at the highest point on the adductor pollicis muscle between the thumb and the index finger. Authors of a 2009 Cochrane review analyze 11 trials with 2317 patients to conclude that the evidence indicates that acupuncture would be a valuable non-pharmacological tool in patients with frequent episodic or chronic tensiontype headaches [29]. In a separate 2009 Cochrane review, authors review 22 trials with 4419 patients, to conclude that available studies indicate that acupuncture is at least as effective as, or possibly more effective than, prophylactic drug treatment, and has fewer adverse effects and that therefore acupuncture should be considered as a treatment option [30]. Pragmatic (practice-oriented) research shows acupuncture to be a cost-effective treatment for headaches [31].

In acupuncture clinics, providers most commonly needle ST36 to enhance immune functioning [32]. For this reason, we term ST36 as the "immuno-enhancing acupoint". ST36 is located $5 \mathrm{~cm}$ below the patella and $2 \mathrm{~cm}$ lateral of the anterior crest of the tibialis anterior muscle [33, 34]. This review makes the case that one way in which acupuncture enhances immune function is through the modulation of $\mathrm{NK}$ cells.

\section{Suggestive Evidence that Acupuncture Stimulates NK Cells}

Limited published studies provide suggestive evidence that acupuncture induces an increase of NK cell activity both in animals and humans. In rats, researchers have shown that carrying out acupuncture on the ST36 acupoint (0.5-1 h a day for 2-3 days) induces, in the spleen, significant increases of NK cell tumoricidal activity and secretion of interleukin-2 (IL-2) and interferon- $\gamma$ (IFN- $\gamma$ ) [35]; and parallel increases in expression of the NK cell receptor CD94, protein tyrosine kinase (PTK) and adhesion molecule VCAM-1 genes, and decreases of protein tyrosine phosphatase (PTP) and SHP1 genes that are critically involved in regulation of NK cell activity [36]. Importantly, researchers have demonstrated that acupuncture stimulation of the ST36 acupoint increases the suppressed NK cell activity in surgically traumatized rats [37]. 
TABle 1: Changes of $\mathrm{CD} 16^{+}$and $\mathrm{CD}^{2} 6^{+} \mathrm{NK}$ cells in peripheral blood following acupuncture.

\begin{tabular}{lcc}
\hline Timing of measurement & $\mathrm{CD}^{+}(\%)$ & $\mathrm{CD}^{+} 6^{+}(\%)$ \\
\hline Before acupuncture & $0.8 \pm 0.2$ & $5.8 \pm 0.7$ \\
First day after acupuncture & $1.6 \pm 0.3^{*}$ & $7.5 \pm 1.0^{*}$ \\
Second day after acupuncture & $2.2 \pm 0.5^{*}$ & $8.5 \pm 1.5^{*}$ \\
Eighth day after acupuncture & $2.1 \pm 0.4^{*}$ & $11.2 \pm 1.8^{* *}$ \\
\hline
\end{tabular}

Data are means \pm SD. Blood samples were drawn from the forearm vein with a syringe containing heparin in 17 healthy volunteers aged 2151 years who received one acupuncture treatment on August 10, 2005. The mononuclear blood cells were separated, stained with fluorescent conjugated monoclonal antibodies and analyzed with fluorescence-activated cell sorter. Table adopted from Yamaguchi et al. [39].

${ }^{*} P<.05,{ }^{*} P<.01$ : statistical significance of differences of the results compared with baseline levels.

In humans, Arranz and colleagues in Spain carried out a clinical trial comparing peripheral blood NK cell cytotoxic activity in 36 female patients suffering from high levels of anxiety before and after acupuncture to 20 healthy controls [38]. At baseline, women with anxiety had NK cell activity 3fold lower than healthy controls $(P<.0001)$. A fraction of the patients were then administered one manual acupuncture treatment with needles retained in place for $30 \mathrm{~min}$ at ST36 and several other points (SI3, HT3, HT5, LI11, PC6, LI4, TH5, CV3, CV4, CV6, CV15, GB34, GB43, SP6, LV2, UB60, KD6, GV20). Immediately and also at $72 \mathrm{~h}$ following the treatment, NK cell activity in the anxious women was still significantly lower than that of the healthy controls $(P<.01$, $P<.05)$, but it progressively and significantly increased relative to the patient's baseline levels $(P<.05, P<.0001)$, respectively. Remarkably, 1 month after finishing a series of 10 acupuncture treatments, the anxious women showed a complete restoration of NK cell cytotoxic activity, which became the same as that in the healthy controls.

Yamaguchi and colleagues in Japan carried out a clinical trial with 17 healthy volunteers from whom they drew blood from a forearm vein $1 \mathrm{~h}$ before and 1,2 and 8 days after treatment [39]. Acupuncture treatment was manual and consisted of insertion of a needle for $5 \mathrm{~s}$ into ST36 and a few other points, such as BL18, BL20 and BL23. The scientists found that patients exhibited progressive and statistically significant increases in the percentage of circulating NK cells subsequent to acupuncture treatment at days 1-8 (compared to baseline). Increased NK cell levels were evidenced by counts of both low affinity Fc $y$ receptor (CD16) and neural cell adhesion molecule (NCAM, CD56) positive peripheral blood mononuclear cells (Table 1). In the same study, authors found a respective 7- and 9-fold increases in the number of IFN- $\gamma$ producing peripheral blood cells subsequent to treatment at days 1 and 8 relative to pretreatment. As NK cells are the major immune cells that rapidly produce IFN- $\gamma$ in response to "danger signals" and IFN- $\gamma$ is an important activator of the immune mechanisms that eliminate cancer cells; we specifically reference this finding below in the course of formally developing our hypothesis.
Petti and colleagues in Italy carried out a clinical trial on 120 patients with pain syndromes [40]. Of the 120 patients, 30 were selected as controls. The remaining 90 patients were randomized into three different treatment groups, one of which assessed NK cell activity. All patients in the treatment groups received acupuncture stimulation of ST36 (in conjunction with the LI4 acupoint) with needles retained in place for $30 \mathrm{~min}$. Peripheral blood of the 30 untreated patients and 30 treated patients per each group was examined for the presence of $\beta$-endorphin and number of NK cells. While untreated patients were examined once, treated patients were examined before, and $30 \mathrm{~min}$ and $24 \mathrm{~h}$ after acupuncture treatment. The scientists found an increase in $\beta$-endorphin after $30 \mathrm{~min}$ of treatment in the peripheral blood of patients who received acupuncture. More importantly, $30 \mathrm{~min}$ and $24 \mathrm{~h}$ after acupuncture treatment, they found that the peripheral blood of $40 \%$ and $50 \%$ of patients, who had low numbers of peripheral blood NK cells before treatment, had increased numbers of NK cells, respectively.

Together, these reviewed studies provide intriguing evidence that acupuncture stimulation modulates NK cell number and function, with the animal studies indicating the immuno-enhancing acupoint (ST36) to be pivotal. For the sake of clarity, we emphasize that we are not claiming this reviewed evidence is conclusive; rather our claim is that there is a sufficiently strong evidential base to warrant theoretical exploration, from a cellular immunology and molecular biological perspective, of possible mechanisms by which acupuncture modulates NK cell number and function. The next section lays the groundwork for such a task by providing an overview of the current understanding of NK cells.

\section{NK Cells Are Important Effectors of Anticancer Immune Mechanisms}

NK cells are essential effector cells of the innate immune system that spontaneously kill transformed and infected cells, and therefore represent the first line of the host immune defense against cancer and pathogens [41-43]. NK cells utilize two major constitutive mechanisms to recognize and kill cancer cells: the secretory/necrotic mechanism, which is mediated by cytolytic activity of the secreted cytotoxic molecules perforin and granzymes and nonsecretory/apoptotic mechanism, which is mediated by transmembrane TNF superfamily ligands (Figure 1) [44, 45]. The secretory/necrotic mechanism is operative against rare leukemia target cells (e.g., in humans, K562 erythroleukemia; in mice, Yac-1 T-cell leukemia) that both express ligands for killer cell activating receptors (KARs) and lack MHC class I molecules. This killing mechanism is induced in NK cells by balanced triggering of KARs (i.e., NKp30, NKp44, NKp46 and NKG2D) with KAR ligands (e.g., the MHC class I homologues MICA and MICB) and disengaging killer cell inhibitory receptors (KIRs) in the absence of MHC class I molecules [46-48]. The non-secretory/apoptotic killing mechanism is operative against all types of cancer cells and 


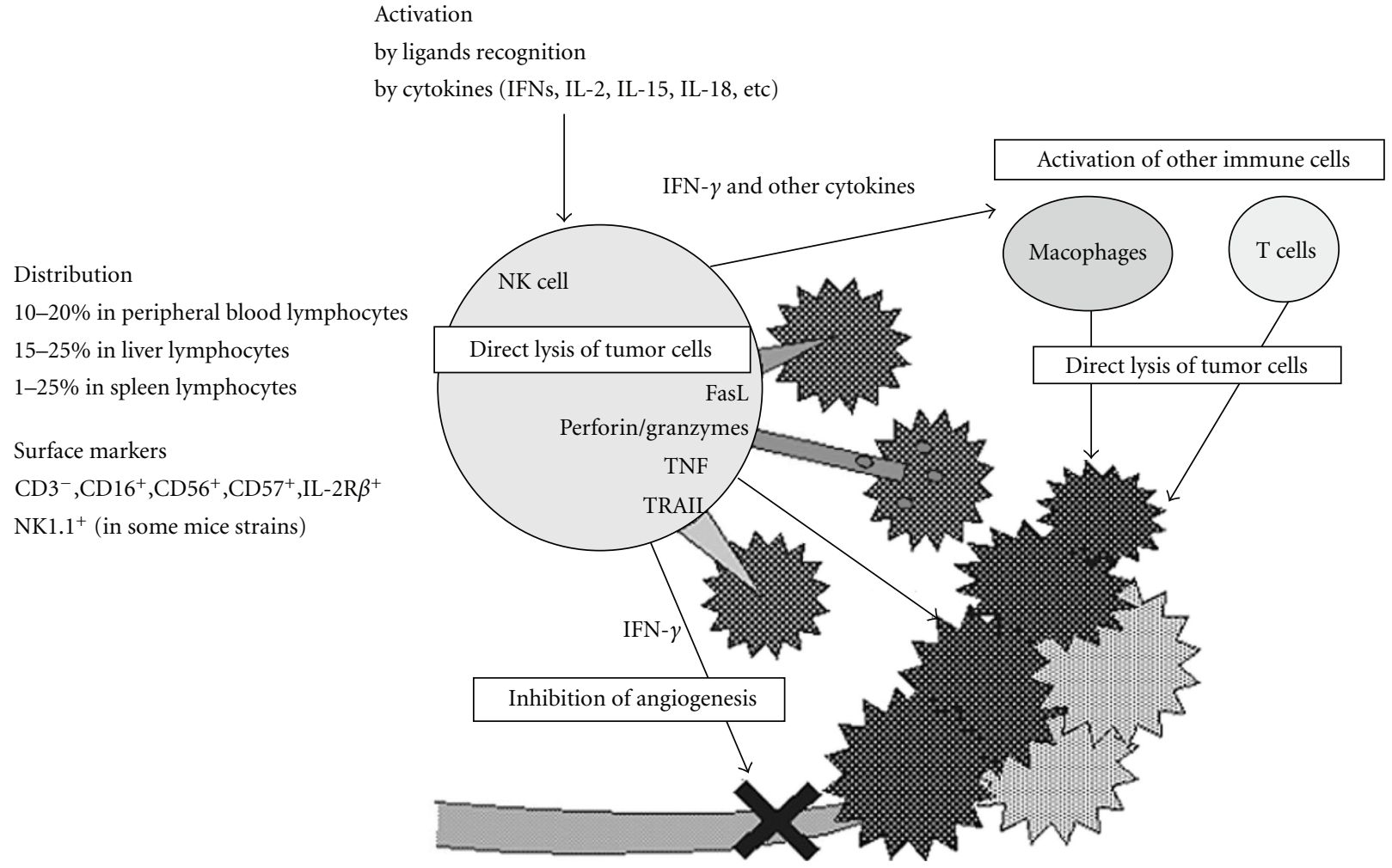

FIGURE 1: NK cells in tumor surveillance. Reproduced with permission from Takeda and Okumura; Evid Based Complement Alternat Med. $2004: 1: 17-27$.

is more efficient than the secretory/necrotic mechanism. It is triggered by a simultaneous engagement of the NK cell transmembrane TNF superfamily ligands TNF, FasL and LT$\alpha 1 \beta 2$ with the corresponding cancer cell transmembrane TNF family receptors TNFR1-TNFR2, Fas and LT- $\beta$ R [42, $44,45,49]$. These two NK cell cytotoxic mechanisms are operative in both rodents and humans. Because normal cells, as opposed to cancer cells, express relatively high levels of MHC class I molecules and low levels of KAR ligands $[50,51]$, and do not express the major proapoptotic TNF family receptors TNFR1, TRAILR1 and TRAILR2 [52], these two cytotoxic mechanisms mediate selective killing of tumor cells without harming normal cells. Using these constitutive and cancer-specific cytotoxic mechanisms, NK cells spontaneously and rapidly eliminate newly formed cancer cells and blood born metastases in vivo, and prevent development of both primary tumors and metastases [41, 42]. To sum up, NK cells play an all-star role in protecting hosts from carcinogenesis and metastases.

In addition to KIRs and KARs, NK cells express a variety of other biologically important receptors, including the receptors for Fc portions of immunoglobulin G (Fc $\gamma$ RIII and Fc $\gamma$ RII) and inflammatory and immunoregulatory cytokines [41, 53]. Therefore, NK cells respond not only to transformed and infected cells but also to immune complexes, inflammation and immune reactions by the increases of their constitutive tumoricidal activities and development of proliferation and production of immunoregulatory cytokines (e.g., IFN- $\gamma$, TNF and GM-CSF) and chemochines (e.g., IL-8, MIP- $1 \alpha$, MIP- $1 \beta$ and RANTES) $[41,42,54-58]$. The newly acquired functions may lead to the remarkable augmentation of NK cell anticancer activities and highly increased direct elimination of cancer cells [42], and induction and regulation of cancer-specific Th1 adaptive immune responses [59], which in concert can destroy and control growth of established tumors and metastases. Among the cytokines, IL- 2 and IFN- $\alpha$ are particularly potent stimulators of NK cells. These two cytokines produce remarkably high growth and tumoricidal activity in NK cells. In response to stimulation by IL- 2 and IFN- $\alpha$, NK cells become capable of destroying all types of cancer cells in a highly efficient way, thereby leading to elimination of established tumors and metastases both in rodents and humans [60, 61]. Because of their stimulating ability, IL-2 and IFN- $\alpha$ have been approved by the FDA and used with a significant therapeutic efficacy to treat patients with advanced malignant melanoma and/or renal cell carcinoma.

NK cells arise from multipotent hematopoietic stem cells (HSCs) that differentiate through a series of defined phenotypic stages. Precursor and immature NK cells were identified in the bone marrow [62]. Cells with an immature NK cell phenotype were also found in murine liver prompting the suggestion that some peripheral tissues could act as reservoirs for less differentiated NK cell progenitors [63]. In humans, a precursor specified to the NK cell lineage was identified in the lymph node [64]. Like other hematopoietic and immune cells, human NK cells can be fully reconstituted in myeloablated individuals by autologous 
or allogeneic bone marrow HSCs [65-67]. Mature NK cells can be generated in vitro from adult blood and bone marrow cells containing HSCs. Both HSCs and mature NK cells have been found in significant numbers in multiple rodent and human tissues/organs including bone marrow, thymus, blood, spleen, lymph nodes, omentum, intestines, skin, lung and liver. This indicates that NK cells are present and can develop in multiple sites [65-67]. The interaction between membrane-bound ligand LT $\alpha 1 \beta 2$ expressed on HSCs and LT $\beta$ R, expressed on stromal cells, as well as stem cell factor (SCF, c-kit ligand), Flt3-L, IL-7 and IL15 , secreted by stromal cells, provide critical signals that induce differentiation cascades of NK cell development from HSCs [65-67]. The number and function of host NK cells is maintained at required levels by a well defined homeostatic mechanism that is mediated by soluble IL-7 and IL-15R $\alpha$ transpresented IL-15 [68].

There are indications that the CNS may regulate anticancer activities of NK cells via neuropeptides. In this regard, endorphins are the most prominent among neuropeptides. Endorphins are endogenous opioid neuropeptides that are produced by the pituitary gland and hypothalamus during strenuous exercise, high psychological excitement, pain, orgasm and death $[69,70]$. $\beta$-endorphin is a cleavage product of pro-opiomelanocortin (POMC), which is also the precursor of adrenocoticotrophic hormone (ACTH). It is produced and released into the blood stream by pituitary gland and into spinal cord and brain tissues by hypothalamic neurons. NK cells sense and respond to endogenous and exogenous opioids [71-74]. $\beta$-endorphin enhances both the number and activity of NK cells in the spleens of mice [71]. The effect appears to be mediated via classical opioid receptors, since augmentation of NK cell activity can be inhibited by the antagonist naloxone [71]. $\beta$-endorphin has also the ability to induce, in mice, increases in the expression of cell adhesion molecules on NK cells and the number of their conjugates with tumor cell targets, as well as the expression of essential cytotoxic molecule of NK cell secretory/necrotic cytotoxicity pathway (granzyme B) [72]. These $\beta$-endorphin-induced molecular changes might be one of the important mechanisms enhancing NK cell tumoricidal activity [72]. Recent studies show that transplantation into the paraventricular nucleus of hypothalamus of in vitro differentiated embryonic hypothalamic neurons producing increased quantities of $\beta$-endorphin results in significant increases in NK cell tumoricidal activity and NK-cell related resistance to $N$-methyl- $N$-nitrosourea induction of prostate cancers in rats [74]. In humans, $\beta$-endorphin has also been shown to induceincrease in NK cell cytotoxic activity [73].

In contrast to the above described stimulatory signals that activate and/or expand NK cells and increase their anticancer activity, there is evidence indicating that the CNS and cancer products have the ability to suppress NK cell anticancer functions. For example, strong chronic emotional or physical stress may induce highly increased and/or prolonged secretion of corticosteroids and endorphins which suppress NK cell anticancer functions [75]. Further, highdose morphine consumption, as well as some cancer products, such as TGF- $\beta$, FasL, oncoproteins [71, 76, 77] and soluble MIC ligands [78], provide strong inhibitory signals for NK cells that counteract NK cell anticancer functions.

In brief, there is compelling evidence that: cytokines, cancer products and CNS neuropeptides regulate NK cell function, that NK cells regulate both innate and adaptive anticancer immune functions, and that NK cells directly kill cancer cells.

\section{Molecular Mechanisms of Action}

There is a coherent body of research indicating acupuncture initiates a cascade of reactions that stimulates the production and blood-borne dissemination of $\beta$-endorphins; the research is largely but not exclusively focused on ST36. Figure 2 traces out the mechanisms by which acupuncture stimulation of ST36 activates the neurotransmitter network in the brain. At the cellular level, needling ST36 induces the enzyme nitric oxide synthase in keratinocytes [79, 80]. In response, these skin cells produce the neurotransmitter nitric oxide [79] which sends signals via the spinal cord to the brain $[34,81,82]$. Simultaneously, NO can also directly stimulate NK cells and induce increases in NK cell tumoricidal activity and proliferation [83]. In the brain, acupuncture stimulation of ST36 elicits widespread and synchronized signals in the cerebro-cerebellar circuit; this is especially marked in the limbic system, which plays a central role in the regulation of immunological functions [33]. Acupuncture-induced signals stimulate the hypothalamus-pituitary-adrenal (HPA) axis to release an endogenous opioid neurotransmitter $(\beta$ endorphin), which travels from the brain via the blood stream to body locations containing immune cells [84].

We begin our synthesis with the statement that acupuncture triggers cross-talk between the neurotransmitter network and the immune system that leads to NK cell activation. This cross-talk is anchored by opiod receptors. When the blood-borne $\beta$-endorphin arrives to lymphoid tissues, it probably binds to opioid receptors expressed on the surface of NK cells $[85,86]$. The bound $\beta$-endorphin stimulates NK cells to increase the expression of cell adhesion molecules, cytotoxic molecules such as granzyme B and perhaps perforin, TNF superfamily ligands $[45,49,52,71-$ 73], and the secretion of cytokines such as IFN- $\gamma$ into the cellular microenvironment [87]. These processes directly and indirectly promote NK cell tumoricidal activities and their ability to eliminate tumor cells and control tumor growth. The molecular processes we are describing provide a theoretical framework for the finding of Yamaguchi and colleagues [39] (discussed above) that acupuncture stimulation is associated with an increase in NK cell expression of cytolytic molecules, tumoricidal activity, quantity and IFN- $\gamma$ secretion in humans.

There is insufficient experimental evidence to precisely identify the cytotoxic mechanisms through which acupuncture stimulation operates to eliminate tumor cells, but we have some clues. It has been reported that $\beta$-endorphin stimulates NK cells to increase the perforin, granzyme B and IFN$\gamma$ levels in ethanol treated Fischer rats [88]. Since acupuncture stimulation also activates secretion of $\beta$-endorphin, we 


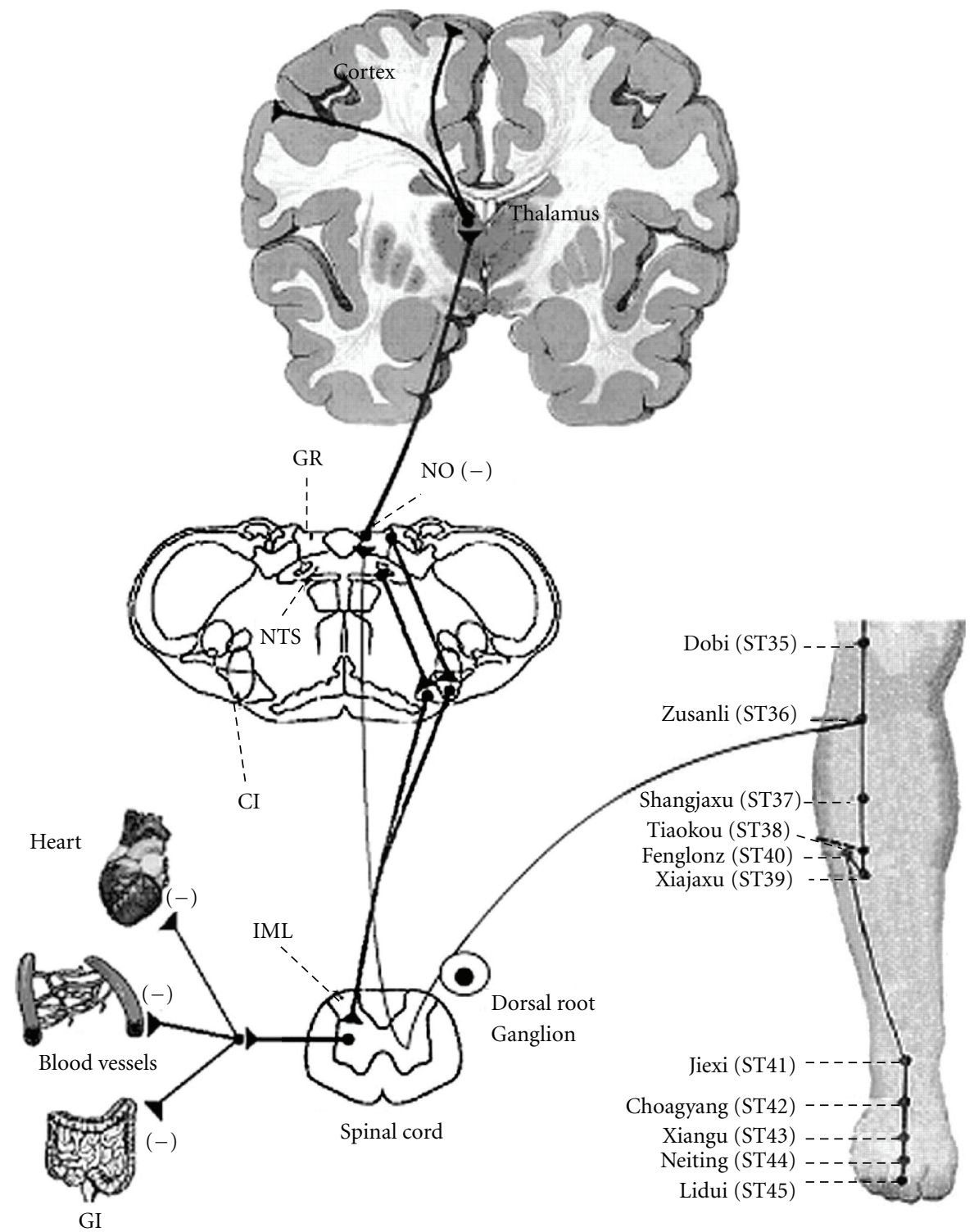

FIGURE 2: Neural circuits related to somatosympathetic reflexes in the gracile-thalamic-cortex pathways. Reproduced with permission from Ma, Evid Based Complement Alternat Med 2004:1:41-47.

suspect that at least one of the pathways through which NK cells stimulated by acupuncture treatment act to eliminate malignant cells is the perforin/granzyme B-mediated secretory/necrotic mechanism of killing. In addition, IFN- $\gamma$, induced by acupuncture stimulation, may promote expression of TNF superfamily ligands on NK cells and dendritic cells and their non-secretory/apoptotic mechanism of killing cancer cells mediated by these molecules [44, 49, 52, 83]. Although the scientific community will continue to sort out the specific details of operative pathways over the coming years, we consider there to be sufficient evidence to formally hypothesize that acupuncture stimulation increases the cytotoxic activity of NK cells (Figure 3 ).

Besides acting as an incubator for the activation of NK cells, the lymphoid tissues also act as an incubator that facilitates increases in NK cell number, which typically varies from 2 to $18 \%$ of the total lymphocytes in human peripheral blood [89]. As described in the previous section, the number of mature NK cells is regulated by continual homeostatic processes that include NK cell precursor proliferation, differentiation and mature NK cell demise. Purine rich box-1 (PU.1) is an important regulatory gene and transcription factor that masters the entire process of NK cell differentiation; it also plays a special role in controlling proliferation during the transition from committed NK cell precursors to immature NK cells [66]. PU.1 is responsible for the regulation of c-Jun. Importantly, acupuncture has been found to increase the expression of c-Jun [90]. Although no directly supporting evidence is available, the finding that acupuncture induces increases in expression of c-Jun, which is regulated by PU-1, suggests that acupuncture might work through the PU.1 pathway to regulate stem 




FIGURE 3: Hypothetic model of the mechanisms how acupuncture stimulates the immune system. Acupuncture stimulation of ST36 acupoint induces release of nitric oxide (NO). NO, a neurotransmiter, stimulates via the sensory nerves, spinal cord and medulla oblongata Gracile nuclceus the lateral hypothalamic area (LHA), where it promotes secretion of opiod peptides such as $\beta$-endorphin. $\beta$-endorphin travels via blood circulation to the spleen and other body locations containing immune cells where it binds to opiod receptors expressed on the surface of NK cells and stimulates NK cells to amplify their expression of cytotoxic molecules and consequently tumoricidal activity, and production of IFN- $\gamma$. This cytokine induces the expression of NK cell receptors and cytokine receptors on NK cells and perhaps cytokine secretion by other immune cells, thereby orchestrating and further amplifying anticancer immune functions. 
TABLE 2: Studies with evidence that acupuncture stimulation modulates NK cell function in humans.

\begin{tabular}{|c|c|c|c|}
\hline Authors, journal, year of publication & $\begin{array}{c}\text { Arranz et al., Am J Chin } \\
\text { Med, } 2007\end{array}$ & $\begin{array}{l}\text { Yamaguchi et al., eCAM, } \\
\qquad 2007\end{array}$ & $\begin{array}{c}\text { Petti et al., J Trad Chin } \\
\text { Med, } 1998\end{array}$ \\
\hline Subjects & $\begin{array}{c}\text { Women with anxiety } \\
\text { (controls, healthy women) }\end{array}$ & Normal individuals & Patients with pain \\
\hline Treatment group & Yes & Yes & Yes \\
\hline Placebo control group & No & No & No \\
\hline Non-placebo control group & Yes & No & Yes \\
\hline Overall Jaded score ${ }^{\mathrm{a}}$ & 2 & 1 & 1 \\
\hline \multicolumn{4}{|l|}{ Scored component items of the Jaded score } \\
\hline Study described as randomized $(\mathrm{Yes}=1 ; \mathrm{No}=0)$ & 0 & 0 & 1 \\
\hline Randomization appropriate $($ Yes $=1 ;$ No $=-1)$ & 0 & 0 & -1 \\
\hline Subject blinded (Yes = $1 ;$ No $=0$ ) & 0 & 0 & 0 \\
\hline Evaluator blinded $($ Yes $=1 ; \mathrm{No}=0)$ & 1 & 0 & 1 \\
\hline $\begin{array}{l}\text { Subjects that withdrew and/or dropped out } \\
\text { described }(\text { Yes }=1 ; \text { No }=0)\end{array}$ & 1 & 1 & 0 \\
\hline
\end{tabular}

${ }^{\mathrm{a}}$ Used to assess quality of methods, with 5 being the highest score possible.

cell differentiation and proliferation leading to the increased production of mature NK cells. Proliferation of NK cells may also be linked to IL-2, a cytokine produced by activated $\mathrm{T}$ cells and dendritic cells. In the previous paragraph, we pointed out that $\beta$-endorphin stimulates NK cells to secrete IFN- $\gamma$ into the cellular microenvironment. $\beta$-endorphin could also simultaneously stimulate activated $\mathrm{T}$ cells and dendritic cells to secrete other cytokines such as IL-2 into the cellular microenvironment [87], which would then promote increases in NK cell proliferation and quantity [90].

We continue our synthesis with the statement that acupuncture-induced cross-talk is also anchored by NK-cell receptors. Korean scientists have utilized mRNA microarray tracking to follow gene expression patterns in NK cells that change in response to needling ST36 in a rat model, relative to a sham treatment group and non-treatment group [36]. The study showed acupuncture stimulation of ST36 produced an increase of mRNA CD94 expression, which coded a lectin-like receptor that paired with NKG2 receptors. In turn, CD94 proteins pair with NKG2C to form activating receptors to induce NK-cell activation via ITAM, a tyrosine-based activation motif in NKG2C. The authors point out that CD94 can also simultaneously form heterodimes with NKG2A to block NK cell activity via ITIM, a tyrosine-based inhibitory motif in NKG2A. In this model, however, acupuncture stimulation of ST36 decreased the expression of SHP-1, which encoded a tyrosine phosphatase required for the inhibitory effect of NKG2A. Acupuncture stimulation of ST36 also induced expression of mRNA PTK that encoded the PTK (including Src, Syk and Zap70 family). PTKs activate downstream proteins that play important roles in multiple cellular processes including proliferation and NK-cell activation. A more recently published, higher quality study confirms many of these findings [91].
Another major NK cell receptor responsible for triggering NK cell cytolytic activity is NKp44 [92, 93], an area investigated in several different ways by different research teams in China. Importantly, the cell surface expression of NKp44 is progressively increased by NK cells during culture with IL2 [93]. Experimental results demonstrate that acupuncture of ST36 increases IL-2, both in mice [94] and in humans $[95,96]$ This finding suggests that acupuncture stimulation of ST36 also produces a sequential molecular cascade along the following lines: needling increases secretion of IL-2, which induces an increased expression of NKp44, thereby leading to enhanced NK cell cytolytic activity.

\section{Assessing the Evidence}

To systematically assess the methodological quality of reviewed studies, we turn to a modified version of the Jadad scale $[97,98]$. The Jaded scale is the scale most commonly used to assess the quality of research in health studies [99]. White and Ernst modified the Jadad scale specifically to assess acupuncture research [100-102]; their modified Jaded scale ranges from 0 to 5 points with a higher score signifying better methodological quality.

Results from the three human studies are statistically significant and consistent but the methodological quality is low, ranging from 1 to 2 points (Table 2 ). One of the primary problems is that the studies lacked either a control group or randomization to a control group. Consequently it is possible that changes in NK cell activity and level may result partially or even completely from reasons other than a direct physiological or psychological connection with acupuncture; such alternative reasons include spontaneous remission, the natural course of waxing and waning of symptoms, and regression to the mean [103]. In contrast, the methodological quality of the cited animal studies is higher 
TABLE 3: Studies with evidence that acupuncture stimulation activates NK cells.

\begin{tabular}{|c|c|c|c|}
\hline Authors, journal, year of publication & $\begin{array}{l}\text { Yu et al., J Neuroimmunol, } \\
1998\end{array}$ & Yu et al., Jpn J Physiol, 1997 & $\begin{array}{l}\text { Choi et al., Neurosci Letter, } \\
2002\end{array}$ \\
\hline Subjects & $\begin{array}{c}\text { BALBrc_qrq.mice, athymic } \\
\text { BALBrc and ICR } \\
\text { nurnu mice, LE rats and } \\
\text { New Zealand white rabbits }\end{array}$ & Inbred F344 rats & Sprague-Dawley rats \\
\hline Treatment group & Yes & Yes & Yes \\
\hline Placebo control group & Yes & Yes & Yes \\
\hline Non-placebo control group & Yes & Yes & Yes \\
\hline Overall Jaded score ${ }^{\mathrm{a}}$ & 2 & 3 & 2 \\
\hline \multicolumn{4}{|l|}{ Scored component items of the Jaded score } \\
\hline Study described as randomized $($ Yes $=1 ;$ No $=0)$ & 0 & 0 & 0 \\
\hline Randomization appropriate $($ Yes $=1 ;$ No $=-1)$ & 0 & 0 & 0 \\
\hline Subject blinded $($ Yes $=1 ;$ No $=0)$ & 1 & 1 & 1 \\
\hline Evaluator blinded $($ Yes $=1 ;$ No $=0)$ & 1 & 1 & 1 \\
\hline $\begin{array}{l}\text { Subjects that withdrew and/or dropped out } \\
\text { Described (Yes }=1 ; \text { No }=0)\end{array}$ & 0 & 1 & 0 \\
\hline
\end{tabular}

${ }^{a}$ Used to assess quality of methods, with 5 being the highest score possible.

TABLE 4: Studies with evidence that acupuncture stimulation leads to proliferation of NK cells.

\begin{tabular}{|c|c|c|c|}
\hline Authors, journal, year of publication & $\begin{array}{c}\text { Kim et al., J } \\
\text { Neuroimmunology, } 2005\end{array}$ & $\begin{array}{c}\text { Yu et al., J } \\
\text { Neuroimmunology, } 1998\end{array}$ & $\begin{array}{l}\text { Choi et al., Neurosci Lett, } \\
2002\end{array}$ \\
\hline Subjects & Sprague-Dawley rats & $\begin{array}{c}\text { BALBrc_qrq.mice, athymic } \\
\text { BALBrc and ICR } \\
\text { nurnu mice, LE rats and } \\
\text { New Zealand white rabbits }\end{array}$ & Sprague-Dawley rats \\
\hline Treatment group & Yes & Yes & Yes \\
\hline Placebo control group & No & Yes & Yes \\
\hline Non-placebo control group & Yes & Yes & Yes \\
\hline Overall Jaded score ${ }^{\mathrm{a}}$ & 3 & 2 & 2 \\
\hline \multicolumn{4}{|l|}{ Jaded score components } \\
\hline Study described as randomized $($ Yes $=1 ;$ No $=0)$ & 0 & 0 & 0 \\
\hline Randomization appropriate $($ Yes $=1 ; \mathrm{No}=-1)$ & 0 & 0 & 0 \\
\hline Subject blinded $($ Yes $=1 ;$ No $=0)$ & 1 & 1 & 1 \\
\hline Evaluator blinded $($ Yes $=1 ; \mathrm{No}=0)$ & 1 & 1 & 1 \\
\hline $\begin{array}{l}\text { Subjects that withdrew and/or dropped out } \\
\text { described (Yes }=1 ; \text { No }=0)\end{array}$ & 1 & 0 & 0 \\
\hline
\end{tabular}

${ }^{a}$ Used to assess quality of methods, with 5 being the highest score possible.

ranging from a Jaded score of 2-5. Looking specifically at the evidence concerning the idea that acupuncture stimulation activates NK cells (Table 3), we observe that the evidence is consistently supportive across all three studies. All three studies assign animals to a treatment group, placebo control group and non-placebo control group; yet the assignment is not random and therefore some of the critiques presented above hold (although not as strongly as with humans because animals are bred to be similar). Evidence regarding the idea that acupuncture stimulation leads to proliferation of NK cells has a similar profile (Table 4). Evidence concerning the idea that acupuncture stimulation modulates expression of NK cell receptors is produced from research designs that are much stronger (Table 5).

\section{Future Studies}

In drawing upon cellular immunology and molecular biological theory to develop an evidence-based hypothesis that acupuncture enhances anticancer immunity, we provide 
TABLE 5: Studies with evidence that acupuncture stimulation modulates expression of NK cell receptors.

\begin{tabular}{|c|c|c|c|c|c|}
\hline Authors, journal, year of publication & $\begin{array}{l}\text { Rho et al., } M o l \\
\text { Cells, } 2008\end{array}$ & $\begin{array}{c}\text { Kim et al., J } \\
\text { Neuroimmunol- } \\
\text { ogy, } \\
2005\end{array}$ & $\begin{array}{c}\text { Xiao et al., Chen } \\
\text { Tzu Yen Chiu, } \\
1992\end{array}$ & $\begin{array}{c}\text { Ma et al., Zhen } \\
\text { Ci and Yan Jiu, } \\
1992\end{array}$ & $\begin{array}{c}\text { Wu et al., } \\
\text { Chung-Kuo } \\
\text { Chung Hsi i } \\
\text { Chieh Ho Tsa } \\
\text { Chih, } 1994\end{array}$ \\
\hline Subjects & $\begin{array}{l}\text { Sprague-Dawley } \\
\text { rats }\end{array}$ & $\begin{array}{l}\text { Sprague-Dawley } \\
\text { rats }\end{array}$ & $\begin{array}{l}\text { People with } \\
\text { rheumatoid } \\
\text { arthritis } \\
\text { (controls, } \\
\text { healthy people) }\end{array}$ & $\mathrm{BALB} / \mathrm{c}$ mice & $\begin{array}{c}\text { Hospital } \\
\text { patients } \\
\text { diagnosed with } \\
\text { a malignant } \\
\text { tumor prior to } \\
\text { surgery }\end{array}$ \\
\hline Treatment group & Yes & Yes & Yes & Yes & Yes \\
\hline Placebo control group & No & No & Yes & No & Yes \\
\hline Non-placebo control group & Yes $^{\mathrm{b}}$ & Yes & Yes & Yes & Yes \\
\hline Jaded score $\mathrm{a}^{\mathrm{a}}$ & 5 & 3 & 2 & 3 & 3 \\
\hline \multicolumn{6}{|l|}{ Jaded score components } \\
\hline Study described as randomized $($ yes $=1 ;$ no $=0$ ) & 1 & 0 & 1 & 1 & 1 \\
\hline Randomization appropriate $($ yes $=1 ;$ no $=-1$ ) & 1 & 0 & -1 & 1 & -1 \\
\hline Subject blinded $($ yes $=1 ;$ no $=0)$ & 1 & 1 & 0 & 1 & 1 \\
\hline Evaluator blinded $($ yes $=1 ;$ no $=0)$ & 1 & 1 & 1 & 1 & 1 \\
\hline $\begin{array}{l}\text { Subjects that withdrew and/or dropped out } \\
\text { described }(\text { yes }=1 ; \text { no }=0)\end{array}$ & 1 & 1 & 1 & 1 & 1 \\
\hline
\end{tabular}

${ }^{a}$ Used to assess quality of methods, with 5 being the highest score possible.

b Authors state "At the same time, the control group of rats $(n=6)$ were restrained in holders without EA stimulation or with EA stimulation at a non-acupoint".

a new framework for considering anew important, unresolved issues, some of which are specific to CAM and others that are more interdisciplinary in nature. Within the field of CAM, there is considerable interest in identifying the extent to which stimulating specific acupoints produces meaningful results beyond the generic effects that accrue from inserting an acupuncture needle into any point on the body. Authors of a Cochrane review, which synthesizes 40 trials involving 4858 patients, conclude that stimulating the P6 acupoint, compared to sham, significantly reduces nausea, vomiting, and the need for rescue antiemetics [25]. Yet another review, one that examines acupuncture studies across a variety of conditions, concludes that clinical trials have failed to demonstrate a difference in effects between sham and true acupuncture [104]. This review provides a new venue to consider this issue of point specific effects, a venue with an outcome that can be objectively and quantitatively assessed. An advocate of generic effects would seemingly expect that administering acupuncture to any single site on the body would increase NK cell cytotoxicity and number. Or at best that needling any one of a number of different acupuncture points would improve NK cell function and quantity in equivalent ways. For example, one of the anonymous reviewers suggested that a point with a segmental relation to the lungs could be very important because the lungs contain significant amounts of NK cells and lymphoid tissues. We read the literature to imply (without conclusively demonstrating) that needling ST36 (compared to both sham and true points) would increase the number and cytotoxicity of NK cells in humans. In many of the animal studies, needling ST36 alone does produce such an effect $[35,36,92]$. That said, we also consider it likely that needling ST36 in conjunction with other well-chosen points would lead to even more effective immune enhancement. Indeed, the human studies we reviewed utilized point combinations [38-40]. Factors that may modulate the extent to which acupuncture improves the quantity and function of NK cells include the nature of the clinician-patient encounter [105], the intensity of acupuncture stimulation [106], and whether or not the clinician achieves "de qi" (achieving a sensation of stimulation after needle insertion [107]).

Another CAM-specific item is that acupuncture likely has beneficial impact upon various other immunological functions including T-cells [40, 108, 109] and B-cells [32]. This review is focused on NK cells, but we consider it likely that scientists could draw upon biomedical concepts to theorize the ways in which acupuncture stimulation enhances T cells, B cells and other immune functions. Such reviews would not be trivial and would likely entail entirely new research papers.

At a much broader level, this review opens up new lines of inquiry about acupuncture and cancer. As of yet, there are no experimental studies directly investigating whether acupuncture stimulation prevents cancer or produces antitumor effects. Such studies could proceed along the following lines. Mice would be randomly assigned to treatment, placebo control and non-stimulation groups. Then, normal or transgenic inbred mice that spontaneously develop cancer would be treated with a carcinogen for study of cancer prevention. Normal inbred mice would be transplanted 
with syngeneic tumor cells to investigate if the therapy has antitumor effects. The treatment groups would receive needle stimulation, the placebo control at another point and the non-stimulation group would not receive any needle stimulation. The mice would be followed for carcinogeninduced tumor appearance or tumor transplant growth and tumor-induced death, respectively. In addition, the mice would be examined for NK cell number and function. At a set period of time, the group results would be compared, thereby yielding either supportive or disconfirming evidence.

An inter-disciplinary item of great importance is the extent to which acupuncture could complement conventional therapies to improve patient outcomes. The human studies that we reviewed are based upon research with, respectively, anxious women, healthy volunteers and people suffering pain. It is important to specifically examine the extent to which acupuncture stimulation comparably enhances immune functioning in patients with the multifactorial disease known as cancer, especially since this population of patients is known to have decreased NK activity [110]. Positive results would, in our opinion, provide strong rationale for concerted efforts to integrate acupuncture into conventional cancer care with the aim of increasing survival and disease-free survival of patients with cancer.

\section{Conclusion}

In this review, we have synthesized heterogeneous research findings with cellular immunological and molecular biological theory to produce the "acupuncture immunoenhancement hypothesis". Broadly, the hypothesis proposes that acupuncture enhances the ability of the immune system to more actively eliminate malignant cells by increasing the ability of NK cells to kill cancer cells. More precisely, the hypothesis trumpets that acupuncture stimulation increases the cytotoxicity of NK cells by promoting cross talk between the neurotransmitter network and immune system that is [1] orchestrated by nitric oxide, $\beta$-endorphin and cytokines and [2] anchored by opioid and NK cell receptors. We intend the "acupuncture immuno-enhancement hypothesis" to provide a focal point for future communication and research about the potential of acupuncture to enhance anticancer immune functions.

\section{Funding}

National Institutes of Health (Grant No. RO1 DE17150) to N.L.V.

\section{Acknowledgments}

The authors thank the editor and anonymous reviewers for providing such a rigorous review for this manuscript; these efforts have lead to a much improved manuscript. They also thank several colleagues for discussing the manuscript with us: Drs Eleanor Axe, Ron Hays, Anahid Jewett, Xiu-Ling Ma, Lawrence Taw and Malcolm Taw. N. L. Vujanovic and W. Li contributed equally to this work.

\section{References}

[1] J. M. Ezzo, M. A. Richardson, A. Vickers et al., "Acupuncturepoint stimulation for chemotherapy-induced nausea or vomiting," Cochrane Database of Systematic Reviews, no. 2, Article ID CD002285, 2006.

[2] K.-K. Hui, E. K. Hui, and M. F. Johnston, "The potential of a person-centered approach in caring for patients with cancer: a perspective from the UCLA Center for East-West Medicine," Integrative Cancer Therapies, vol. 5, no. 1, pp. 5662, 2006.

[3] B. Yan, K. Li, J. Xu et al., "Acupoint-specific fMRI patterns in human brain," Neuroscience Letters, vol. 383, no. 3, pp. 236240, 2005.

[4] C. Créac'h, P. Henry, J. M. Caille, and M. Allard, "Functional MR imaging analysis of pain-related brain activation after acute mechanical stimulation," American Journal of Neuroradiology, vol. 21, no. 8, pp. 1402-1406, 2000.

[5] A. J. Cohen, A. Menter, and L. Hale, "Acupuncture: role in comprehensive cancer care-a primer for the oncologist and review of the literature," Integrative Cancer Therapies, vol. 4, no. 2, pp. 131-143, 2005.

[6] D. S. Rosenthal and E. Dean-Clower, "Integrative medicine in hematology/oncology: benefits, ethical considerations, and controversies," Hematology, vol. 2005, pp. 491-497, 2005.

[7] N. Samuels, "Acupuncture for cancer patients: why not?" Harefuah, vol. 141, no. 7, pp. 608-666, 2002.

[8] A. J. Vickers, D. J. Straus, B. Fearon, and B. R. Cassileth, "Acupuncture for postchemotherapy fatigue: a phase II study," Journal of Clinical Oncology, vol. 22, no. 9, pp. 17311735, 2004.

[9] M. F. Johnston, R. D. Hays, and K.-K. Hui, "Evidencebased effect size estimation: an illustration using the case of acupuncture for cancer-related fatigue," BMC Complementary and Alternative Medicine, vol. 9, article 1, 2009.

[10] A. White, "A cumulative review of the range and incidence of significant adverse events associated with acupuncture," Acupuncture in Medicine, vol. 22, no. 3, pp. 122-133, 2004.

[11] M. Tagliaferri, I. Cohen, and D. Tripathy, "Complementary and alternative medicine in early-stage breast cancer," Seminars in Oncology, vol. 28, no. 1, pp. 121-134, 2001.

[12] J. S. Jacobson, S. B. Workman, and F. Kronenberg, "Research on complementary/alternative medicine for patients with breast cancer: a review of the biomedical literature," Journal of Clinical Oncology, vol. 18, no. 3, pp. 668-683, 2000.

[13] J. M. Metz, “'Alternative medicine' and the cancer patient: an overview," Medical and Pediatric Oncology, vol. 34, no. 1, pp. 20-26, 2000.

[14] D. J. L. Joske, A. Rao, and L. Kristjanson, "Critical review of complementary therapies in haemato-oncology," Internal Medicine Journal, vol. 36, no. 9, pp. 579-586, 2006.

[15] O. Caspi, T. Shalom, and J. Holexa, "Informed consent in complementary and alternative medicine," Evidence-Based Complementary and Alternative Medicine, 2009.

[16] M. J. Smyth, Y. Hayakawa, K. Takeda, and H. Yagita, "New aspects of natural-killer-cell surveillance and therapy of cancer," Nature Reviews Cancer, vol. 2, no. 11, pp. 850-861, 2002.

[17] A. Cerwenka and L. L. Lanier, "Natural killer cells, viruses and cancer," Nature Reviews Immunology, vol. 1, no. 1, pp. 41-49, 2001. 
[18] A. Obata-Onai, S.-I. Hashimoto, N. Onai et al., "Comprehensive gene expression analysis of human NK cells and $\mathrm{CD}^{+} \mathrm{T}$ lymphocytes," International Immunology, vol. 14, no. 10, pp. 1085-1098, 2002.

[19] A. A. Rabinstein and L. M. Shulman, "Acupuncture in clinical neurology," Neurologist, vol. 9, no. 3, pp. 137-148, 2003.

[20] C.-H. Zhao, M. J. Stillman, and T. D. Rozen, "Traditional and evidence-based acupuncture in headache management: theory, mechanism, and practice," Headache, vol. 45, no. 6, pp. 716-730, 2005.

[21] S. Lim, "WHO standard acupuncture point locations," Evidence-Based Complementary and Alternative Medicine, vol. 7, no. 2, pp. 167-168, 2010.

[22] J. Shen, N. Wenger, J. Glaspy et al., "Electroacupuncture for control of myeloablative chemotherapy-induced emesis: a randomized controlled trial," Journal of the American Medical Association, vol. 284, no. 21, pp. 2755-2761, 2000.

[23] D. J. Cook, C. D. Mulrow, and R. B. Haynes, "Systematic reviews: synthesis of best evidence for clinical decisions," Annals of Internal Medicine, vol. 126, no. 5, pp. 376-380, 1997.

[24] J. Ezzo, K. Streitberger, and A. Schneider, "Cochrane systematic reviews examine P6 acupuncture-point stimulation for nausea and vomiting," Journal of Alternative and Complementary Medicine, vol. 12, no. 5, pp. 489-495, 2006.

[25] A. Lee and L. T. Y. Fan, "Stimulation of the wrist acupuncture point P6 for preventing postoperative nausea and vomiting," Cochrane Database of Systematic Reviews, no. 2, Article ID CD003281, 2009.

[26] D. Jewell and G. Young, "Interventions for nausea and vomiting in early pregnancy," Cochrane Database of Systematic Reviews, no. 2, Article ID CD000145, 2000.

[27] M. Arnberger, K. Stadelmann, P. Alischer, R. Ponert, A. Melber, and R. Greif, "Monitoring of neuromuscular blockade at the P6 acupuncture point reduces the incidence of postoperative nausea and vomiting," Anesthesiology, vol. 107, no. 6, pp. 903-908, 2007.

[28] Y. F. Shen and G. Goddard, "The short-term effects of acupuncture on myofascial pain patients after clenching," Pain Practice, vol. 7, no. 3, pp. 256-264, 2007.

[29] K. Linde, G. Allais, B. Brinkhaus, E. Manheimer, A. Vickers, and A. R. White, "Acupuncture for tension-type headache," Cochrane Database of Systematic Reviews, no. 1, Article ID CD007587, 2009.

[30] K. Linde, G. Allais, B. Brinkhaus, E. Manheimer, A. Vickers, and A. R. White, "Acupuncture for migraine prophylaxis," Cochrane Database of Systematic Reviews, no. 1, Article ID CD001218, 2009.

[31] C. M. Witt, T. Reinhold, S. Jena, B. Brinkhaus, and S. N. Willich, "Cost-effectiveness of acupuncture treatment in patients with headache," Cephalalgia, vol. 28, no. 4, pp. 334345, 2008.

[32] Y.-K. Yim, H. Lee, K.-E. Hong et al., "Electro-acupuncture at acupoint ST36 reduces inflammation and regulates immune activity in collagen-induced arthritic mice," Evidence-Based Complementary and Alternative Medicine, vol. 4, no. 1, pp. 51-57, 2007.

[33] K. K. S. Hui, J. Liu, N. Makris et al., "Acupuncture modulates the limbic system and subcortical gray structures of the human brain: evidence from fMRI studies in normal subjects," Human Brain Mapping, vol. 9, no. 1, pp. 13-25, 2000.
[34] S. X. Ma, "Neurobiology of acupuncture: toward CAM," Evidence-Based Complementary and Alternative Medicine, vol. 1, pp. 41-47, 2004.

[35] Y. Yu, T. Kasahara, T. Sato et al., "Enhancement of splenic interferon- $\gamma$, interleukin-2, and NK cytotoxicity by S36 acupoint acupuncture in F344 rats," Japanese Journal of Physiology, vol. 47, no. 2, pp. 173-178, 1997.

[36] C. K. Kim, G. S. Choi, S. D. Oh et al., "Electroacupuncture up-regulates natural killer cell activity: identification of genes altering their expressions in electroacupuncture induced upregulation of natural killer cell activity," Journal of Neuroimmunology, vol. 168, no. 1-2, pp. 144-153, 2005.

[37] L.-N. Du, J.-W. Jiang, G.-C. Wu, and X.-D. Cao, "Naloxone and electroacunpunture (EA) improve the immune function of traumatized rats," Sheng Li Xue Bao, vol. 50, no. 6, pp. 636642, 1998.

[38] L. Arranz, N. Guayerbas, L. Siboni, and M. De la Fuente, "Effect of acupuncture treatment on the immune function impairment found in anxious women," American Journal of Chinese Medicine, vol. 35, no. 1, pp. 35-51, 2007.

[39] N. Yamaguchi, T. Takahashi, M. Sakuma et al., "Acupuncture regulates leukocyte subpopulations in human peripheral blood," Evidence-Based Complementary and Alternative Medicine, vol. 4, no. 4, pp. 447-453, 2007.

[40] F. Petti, A. Bangrazi, A. Liguori, G. Reale, and F. Ippoliti, "Effects of acupuncture on immune response related to opioid-like peptides," Journal of Traditional Chinese Medicine, vol. 18, no. 1, pp. 55-63, 1998.

[41] G. Trinchieri, "Biology of natural killer cells," Advances in Immunology, vol. 47, pp. 187-376, 1989.

[42] N. L. Vujanovic, P. Basse, R. B. Herberman, and T. L. Whiteside, "Antitumor functions of natural killer cells and control of metastases," Methods: A Companion to Methods in Enzymology, vol. 9, no. 2, pp. 394-408, 1996.

[43] C. A. Biron, K. B. Nguyen, G. C. Pien, L. P. Cousens, and T. P. Salazar-Mather, "Natural killer cells in antiviral defense: function and regulation by innate cytokines," Annual Review of Immunology, vol. 17, pp. 189-220, 1999.

[44] N. L. Vujanovic, S. Nagashima, R. B. Herberman, and T. L. Whiteside, "Nonsecretory apoptotic killing by human NK cells," Journal of Immunology, vol. 157, no. 3, pp. 1117-1126, 1996.

[45] N. L. Vujanovic, "Role of TNF family ligands in antitumor activity of natural killer cells," International Reviews of Immunology, vol. 20, no. 3-4, pp. 415-437, 2001.

[46] L. L. Lanier, "NK cell receptors," Annual Review of Immunology, vol. 16, pp. 359-393, 1998.

[47] A. Moretta, R. Biassoni, C. Bottino, M. C. Mingari, and L. Moretta, "Natural cytotoxicity receptors that trigger human NK-cell-mediated cytolysis," Immunology Today, vol. 21, no. 5, pp. 228-234, 2000.

[48] W. M. Yokoyama and B. F. M. Plougastel, "Immune functions encoded by the natural killer gene complex," Nature Reviews Immunology, vol. 3, no. 4, pp. 304-316, 2003.

[49] Y. Kashii, R. Giorda, R. B. Herberman, T. L. Whiteside, and N. L. Vujanovic, "Constitutive expression and role of the tumor necrosis factor family ligands in apoptotic killing by human natural killer cells," The Journal of Immunology, vol. 163, pp. 5358-5366, 1999.

[50] E. Vivier and C. A. Biron, "A pathogen receptor on natural killer cells,” Science, vol. 296, no. 5571, pp. 1248-1249, 2002. 
[51] M. Gleimer and P. Parham, "Stress management: MHC class I and class I-like molecules as reporters of cellular stress," Immunity, vol. 19, no. 4, pp. 469-477, 2003.

[52] G. Lu, B. M. Janjic, J. Janjic, T. L. Whiteside, W. J. Storkus, and N. L. Vujanovic, "Innate direct anticancer effector function of human immature dendritic cells. II. Role of TNF, lymphotoxin- $\alpha 1 \beta 2$, Fas ligand, and TNF-related apoptosisinducing ligand," Journal of Immunology, vol. 168, no. 4, pp. 1831-1839, 2002.

[53] A. Sulica, P. Morel, D. Metes, and R. B. Herberman, "Igbinding receptors on human NK cells as effector and regulatory surface molecules," International Reviews of Immunology, vol. 20, no. 3-4, pp. 371-414, 2001.

[54] L. L. Lanier and J. H. Phillips, "Natural killer cells," Current Opinion in Immunology, vol. 4, no. 1, pp. 38-42, 1992.

[55] D. Vitolo, N. L. Vujanovic, H. Rabinowich, M. Schlesinger, R. B. Herberman, and T. L. Whiteside, "Rapid IL-2-induced adherence of human natural killer cells: expression of mRNA for cytokines and IL-2 receptors in adherent NK cells," Journal of Immunology, vol. 151, no. 4, pp. 1926-1937, 1993.

[56] D. Peritt, S. Robertson, G. Gri, L. Showe, M. Aste-Amezaga, and G. Trinchieri, "Cutting edge: differentiation of human NK cells into NK1 and NK2 subsets," Journal of Immunology, vol. 161, no. 11, pp. 5821-5824, 1998.

[57] A. Oliva, A. L. Kinter, M. Vaccarezza et al., "Natural killer cells from human immunodeficiency virus (HIV)-infected individuals are an important source of CC-chemokines and suppress HIV-1 entry and replication in vitro," Journal of Clinical Investigation, vol. 102, no. 1, pp. 223-231, 1998.

[58] M. A. Cooper, T. A. Fehniger, and M. A. Caligiuri, "The biology of human natural killer-cell subsets," Trends in Immunology, vol. 22, no. 11, pp. 633-640, 2001.

[59] F. J. Kos and E. G. Engleman, "Requirement for natural killer cells in the induction of cytotoxic T cells," Journal of Immunology, vol. 155, no. 2, pp. 578-584, 1995.

[60] S. A. Rosenberg, "Progress in the development of immunotherapy for the treatment of patients with cancer," Journal of Internal Medicine, vol. 250, no. 6, pp. 462-475, 2001.

[61] S. Moschos and J. M. Kirkwood, "Present role and future potential of type I interferons in adjuvant therapy of high-risk operable melanoma," Cytokine and Growth Factor Reviews, vol. 18, no. 5-6, pp. 451-458, 2007.

[62] E. E. Rosmaraki, I. Douagi, C. Roth, F. Colucci, A. Cumano, and J. P. Di Santo, "Identification of committed NK cell progenitors in adult murine bone marrow," European Journal of Immunology, vol. 31, no. 6, pp. 1900-1909, 2001.

[63] S. Kim, K. Iizuka, H.-S. P. Kang et al., "In vivo developmental stages in murine natural killer cell maturation," Nature Immunology, vol. 3, no. 6, pp. 523-528, 2002.

[64] A. G. Freud, B. Becknell, S. Roychowdhury et al., "A human $\mathrm{CD} 34^{+}$subset resides in lymph nodes and differentiates into CD56bright natural killer cells," Immunity, vol. 22, no. 3, pp. 295-304, 2005.

[65] B. Blom and H. Spits, "Development of human lymphoid cells," Annual Review of Immunology, vol. 24, pp. 287-320, 2006.

[66] J. P. Di Santo, "Natural killer cell developmental pathways: a question of balance," Annual Review of Immunology, vol. 24, pp. 257-286, 2006.

[67] F. Colucci, M. A. Caligiuri, and J. P. Di Santo, "What does it take to make a natural killer?" Nature Reviews Immunology, vol. 3, no. 5, pp. 413-425, 2003.
[68] P. R. Burkett, R. Koka, M. Chien, S. Chai, D. L. Boone, and A. Ma, "Coordinate expression and trans presentation of interleukin (IL)-15R $\alpha$ and IL-15 supports natural killer cell and memory CD8 ${ }^{+} \mathrm{T}$ cell homeostasis," Journal of Experimental Medicine, vol. 200, no. 7, pp. 825-834, 2004.

[69] F. Cesselin, “Opioid and anti-opioid peptides," Fundamental and Clinical Pharmacology, vol. 9, no. 5, pp. 409-433, 1995.

[70] M. Narita and L. F. Tseng, "Evidence for the existence of the $\beta$-endorphin-sensitive " $\varepsilon$-opioid receptor" in the brain: the mechanisms of $\varepsilon$-mediated antinociception," Japanese Journal of Pharmacology, vol. 76, no. 3, pp. 233-253, 1998.

[71] J. Kowalski, "Effect of enkephalins and endorphins on cytotoxic activity of natural killer cells and macrophages/monocytes in mice," European Journal of Pharmacology, vol. 326, no. 2-3, pp. 251-255, 1997.

[72] K. Wakao, I. Matsuzaki, K. Terao, M. Inoue-Murayama, N. Shimojo, and Y. Murayama, "Involvement of granzyme B expression in the enhancement of natural killer activity by $\beta$-endorphin," Brain, Behavior, and Immunity, vol. 14, no. 1, pp. 27-40, 2000.

[73] A. Borman, Z. Ciepielewski, D. Wrona et al., "Small doses of morphine can enhance NK cell cytotoxicity in pigs," International Immunopharmacology, vol. 9, no. 3, pp. 277283, 2009.

[74] D. K. Sarkar, N. I. Boyadjieva, C. P. Chen et al., "Cyclic adenosine monophosphate differentiated $\beta$-endorphin neurons promote immune function and prevent prostate cancer growth," Proceedings of the National Academy of Sciences of the United States of America, vol. 105, no. 26, pp. 9105-9110, 2008.

[75] F. S. Dhabhar, "Acute stress enhances while chronic stress suppresses skin immunity: the role of stress hormones and leukocyte trafficking," Annals of the New York Academy of Sciences, vol. 917, pp. 876-893, 2000.

[76] M. P. Yeager, C. T. Yu, A. S. Campbell, M. Moschella, and P. M. Guyre, "Effect of morphine and $\beta$-endorphin on human Fc receptor-dependent and natural killer cell functions," Clinical Immunology and Immunopathology, vol. 62, no. 3, pp. 336-343, 1992.

[77] T. L. Whiteside and H. Rabinowich, "The role of Fas/FasL in immunosuppression induced by human tumors," Cancer Immunology Immunotherapy, vol. 46, no. 4, pp. 175-184, 1998.

[78] M. Gleimer and P. Parham, "Stress management: MHC class I and class I-like molecules as reporters of cellular stress," Immunity, vol. 19, no. 4, pp. 469-477, 2003.

[79] S.-X. Ma, X.-Y. Li, T. Sakurai, and M. Pandjaitan, "Evidence of enhanced non-enzymatic generation of nitric oxide on the skin surface of acupuncture points: an innovative approach in humans," Nitric Oxide, vol. 17, no. 2, pp. 60-68, 2007.

[80] S.-X. Ma, A. Ji, M. Pandjaitan, and G. Ojije, "Enhanced nitric oxide release/synthesis in the posterior hypothalamus during nitroglycerin tolerance in rats," European Journal of Pharmacology, vol. 472, no. 3, pp. 179-187, 2003.

[81] D. S. Bredt and S. H. Snyder, "Nitric oxide, a novel neuronal messenger," Neuron, vol. 8, no. 1, pp. 3-11, 1992.

[82] S.-X. Ma, J. Ma, G. Moise, and X.-Y. Li, "Responses of neuronal nitric oxide synthase expression in the brainstem to electroacupuncture Zusanli (ST 36) in rats," Brain Research, vol. 1037, no. 1-2, pp. 70-77, 2005.

[83] M. G. Cifone, S. Ulisse, and A. Santoni, "Natural killer cells and nitric oxide," International Immunopharmacology, vol. 1, no. 8 , pp. 1513-1524, 2001. 
[84] Z. H. Cho, S. C. Hwang, E. K. Wong et al., "Neural substrates, experimental evidences and functional hypothesis of acupuncture mechanisms," Acta Neurologica Scandinavica, vol. 113, no. 6, pp. 370-377, 2006.

[85] Y. Yu, T. Kasahara, T. Sato et al., "Role of endogenous interferon- $\gamma$ on the enhancement of splenic NK cell activity by electroacupuncture stimulation in mice," Journal of Neuroimmunology, vol. 90, no. 2, pp. 176-186, 1998.

[86] G. S. Choi, S. D. Oha, J. B. Han et al., "Modulation of natural killer cell activity affected by electroacupuncture through lateral hypothalamic area in rats," Neuroscience Letters, vol. 329, no. 1, pp. 1-4, 2002.

[87] Y. Yu, T. Kasahara, T. Sato et al., "Enhancement of splenic interferon- $\gamma$, interleukin-2, and NK cytotoxicity by S36 acupoint acupuncture in F344 rats," Japanese Journal of Physiology, vol. 47, no. 2, pp. 173-178, 1997.

[88] M. Dokur, P. C. Cui, J. P. Advis, and D. K. Sarkar, " $\beta$-endorphin modulation of interferon- $\gamma$, perforin and granzyme B levels in splenic NK cells: effects of ethanol," Journal of Neuroimmunology, vol. 166, no. 1-2, pp. 29-38, 2005.

[89] E. Vivier, E. Tomasello, M. Baratin, T. Walzer, and S. Ugolini, "Functions of natural killer cells," Nature Immunology, vol. 9, no. 5, pp. 503-510, 2008.

[90] C. Ventura, "CAM and cell fate targeting: molecular and energetic insights into cell growth and differentiation," Evidence-Based Complementary and Alternative Medicine, vol. 2, no. 3, pp. 277-283, 2005.

[91] S.-W. Rho, G.-S. Choi, E.-J. Ko et al., "Molecular changes in remote tissues induced by electro-acupuncture stimulation at acupoint ST36," Molecules and Cells, vol. 25, no. 2, pp. 178$183,2008$.

[92] R. Biasoni, C. Bottino, C. Cantoni, and A. Moretta, "Human natural killer receptors and their ligands," in Current Protocols in Immunology, chapter 14: unit 14.10, John Wiley \& Sons, New York, NY, USA, 2002.

[93] M. Vitale, C. Bottino, S. Sivori et al., "NKp44, a novel triggering surface molecule specifically expressed by activated natural killer cells, is involved in non-major histocompatibility complex-restricted tumor cell lysis," Journal of Experimental Medicine, vol. 187, no. 12, pp. 2065-2072, 1998.

[94] Z. Ma, Y. Wang, and Q. Fan, "The influence of acupuncture on interleukin 2 interferon-natural killer cell regulatory network of kidney-deficiency mice," Zhen Ci and Yan Jiu, vol. 17, no. 2, pp. 139-142, 1992.

[95] J. Xiao, X. Liu, L. Sun et al., "Experimental study on the influence of acupuncture and moxibustion on interleukin2 in patients with rheumatoid arthritis," Chen Tzu Yen Chiu, vol. 17, no. 2, pp. 126-132, 1992.

[96] B. Wu, R. X. Zhou, and M. S. Zhou, "Effect of acupuncture on interleukin-2 level and NK cell immunoactivity of peripheral blood of malignant tumor patients," Chung-Kuo Chung Hsi i Chieh Ho Tsa Chih, vol. 14, pp. 537-539, 1994.

[97] A. R. Jadad, R. A. Moore, D. Carroll et al., "Assessing the quality of reports of randomized clinical trials: is blinding necessary?" Controlled Clinical Trials, vol. 17, no. 1, pp. 1-12, 1996.

[98] A. R. White and E. Ernst, "A systematic review of randomized controlled trials of acupuncture for neck pain," Rheumatology, vol. 38, no. 2, pp. 143-147, 1999.

[99] S. A. Olivo, L. G. Macedo, I. C. Gadotti, J. Fuentes, T. Stanton, and D. J. Magee, "Scales to assess the quality of randomized controlled trials: a systematic review," Physical Therapy, vol. 88, no. 2, pp. 156-175, 2008.
[100] M. S. Lee, B.-C. Shin, L. K. P. Suen, T.-Y. Park, and E. Ernst, "Auricular acupuncture for insomnia: a systematic review," International Journal of Clinical Practice, vol. 62, no. 11, pp. 1744-1752, 2008.

[101] M. S. Lee, B.-C. Shin, and E. Ernst, "Acupuncture for rheumatoid arthritis: a systematic review," Rheumatology, vol. 47, no. 12, pp. 1747-1753, 2008.

[102] M. S. Lee, B.-C. Shin, J. C. Kong, and E. Ernst, "Effectiveness of acupuncture for Parkinson disease: a systematic review," Movement Disorders, vol. 23, no. 11, pp. 1505-1515, 2008.

[103] F. G. Miller and T. J. Kaptchuk, "The power of context: reconceptualizing the placebo effect," Journal of the Royal Society of Medicine, vol. 101, no. 5, pp. 222-225, 2008.

[104] H. H. Moffet, "Sham acupuncture may be as efficacious as true acupuncture: a systematic review of clinical trials," Journal of Alternative and Complementary Medicine, vol. 15, no. 3, pp. 213-216, 2009.

[105] T. J. Kaptchuk, J. M. Kelley, L. A. Conboy et al., "Components of placebo effect: randomised controlled trial in patients with irritable bowel syndrome," BMJ, vol. 336, no. 7651, pp. 9991003, 2008.

[106] H. G. Endres, G. Böwing, H.-C. Diener et al., "Acupuncture for tension-type headache: a multicentre, sham-controlled, patient-and observer-blinded, randomised trial," Journal of Headache and Pain, vol. 8, no. 5, pp. 306-314, 2007.

[107] J. Kong, R. Gollub, T. Huang et al., "Acupuncture de qi, from qualitative history to quantitative measurement," Journal of Alternative and Complementary Medicine, vol. 13, no. 10, pp. 1059-1070, 2007.

[108] S. Joos, C. Schott, H. Zou, V. Daniel, and E. Martin, "Immunomodulatory effects of acupuncture in the treatment of allergic asthma: a randomized controlled study," Journal of Alternative and Complementary Medicine, vol. 6, no. 6 , pp. 519-525, 2000.

[109] F. Ye, S. Chen, and W. Liu, "Effects of electro-acupuncture on immune function after chemotherapy in 28 cases," Journal of Traditional Chinese Medicine, vol. 22, pp. 21-23, 2002.

[110] A. Jewett, C. Head, and N. A. Cacalano, "Emerging mechanisms of immunosuppression in oral cancers," Journal of Dental Research, vol. 85, no. 12, pp. 1061-1073, 2006. 


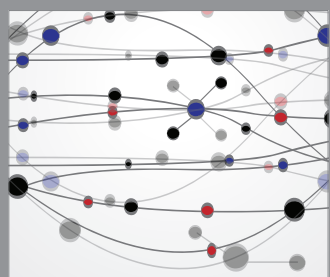

The Scientific World Journal
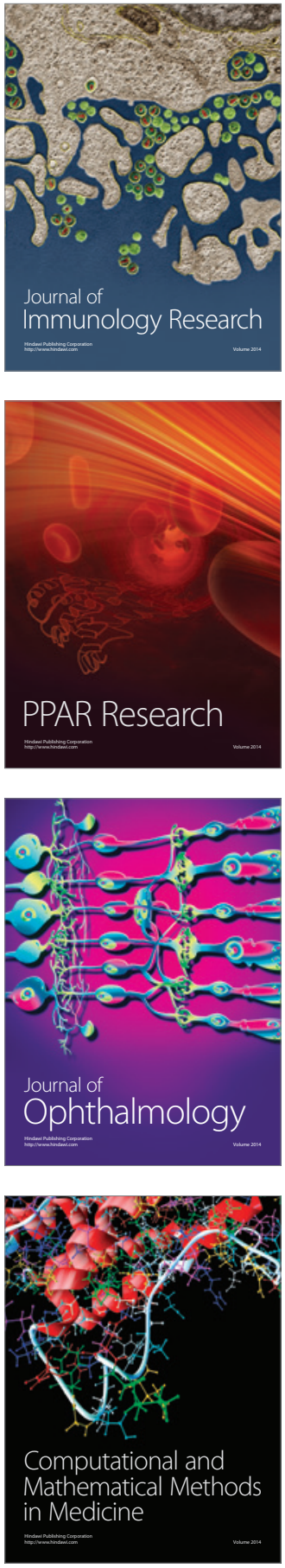

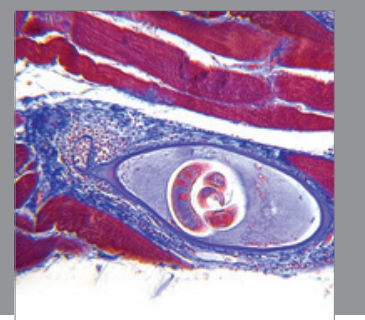

Gastroenterology

Research and Practice
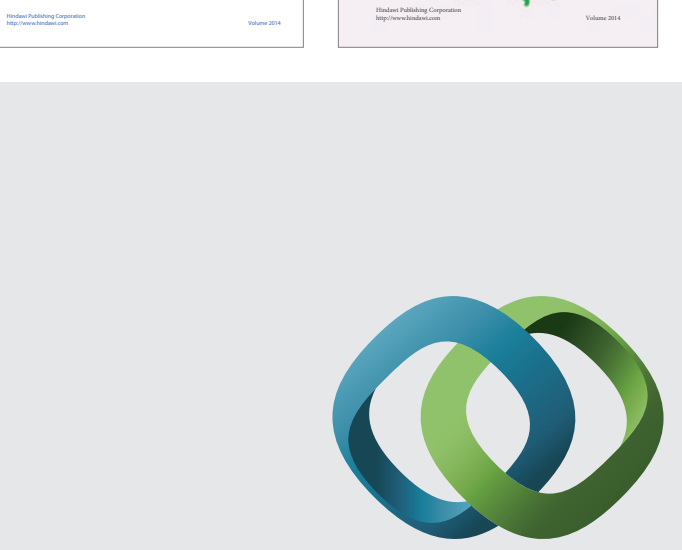

\section{Hindawi}

Submit your manuscripts at

http://www.hindawi.com
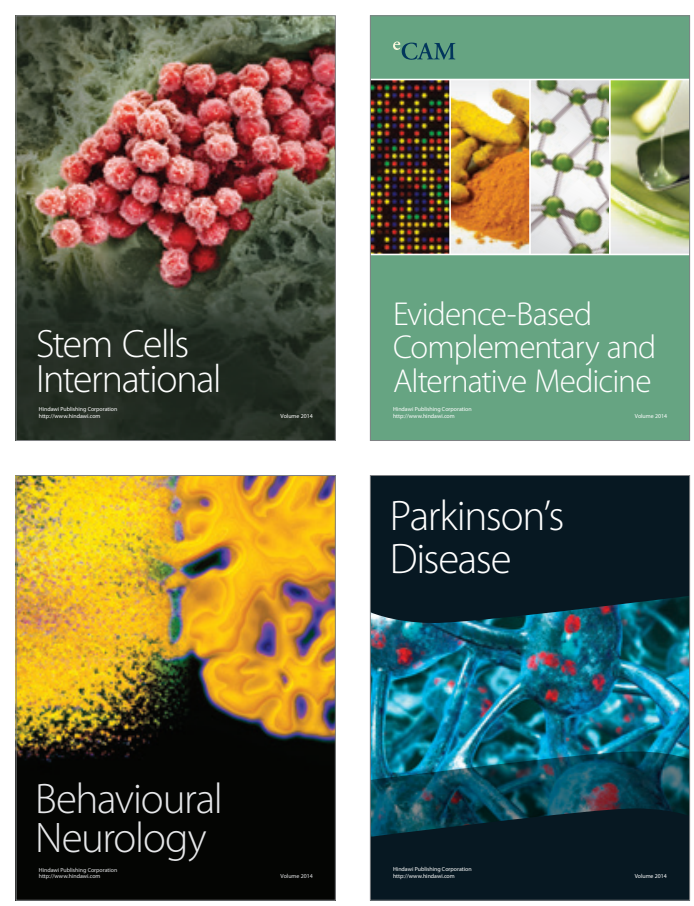

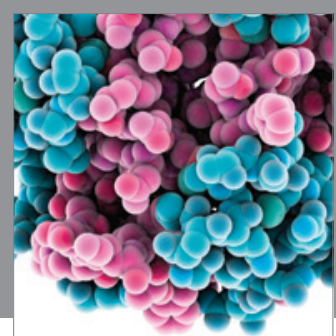

Journal of
Diabetes Research

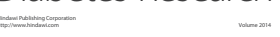

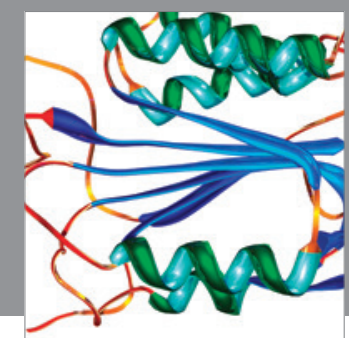

Disease Markers
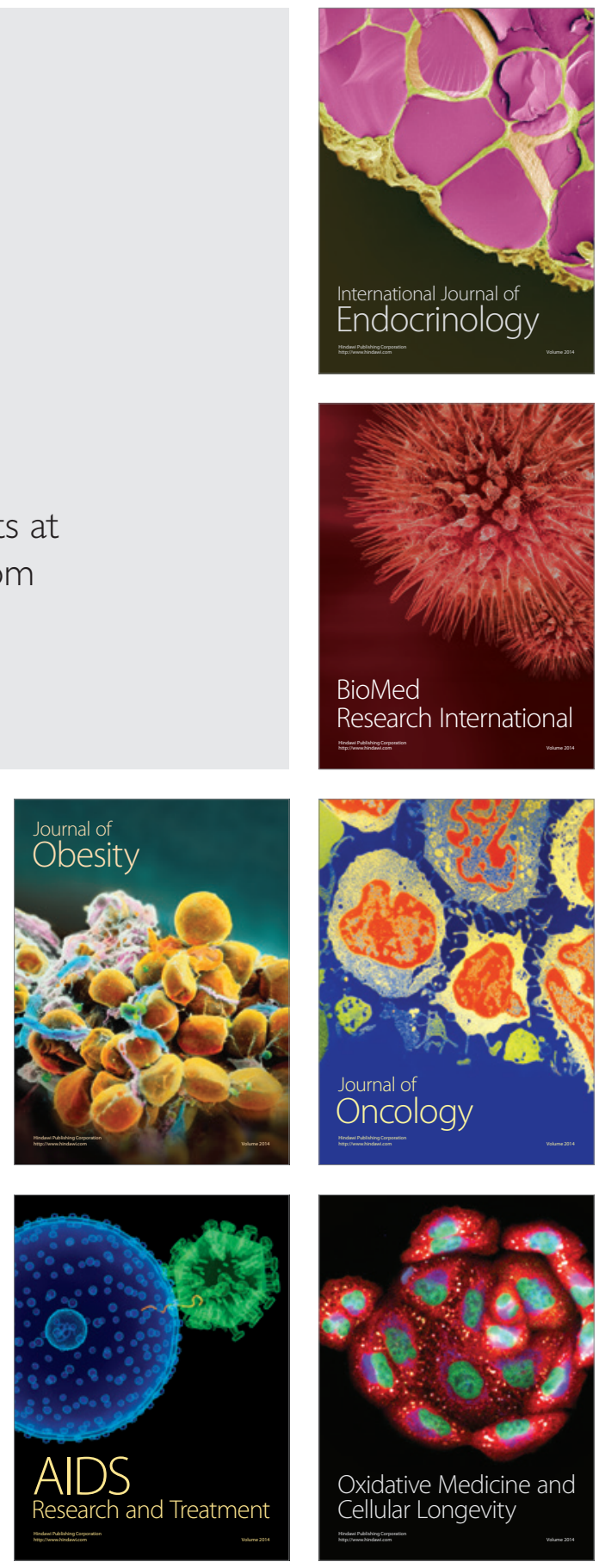